\title{
Environmental induction and phenotypic retention of adaptive maternal effects
}

\author{
Alexander V Badyaev* and Kevin P Oh
}

\author{
Address: Department of Ecology and Evolutionary Biology, University of Arizona, Tucson, AZ 85721, USA \\ Email: Alexander V Badyaev* - abadyaev@email.arizona.edu; Kevin P Oh - koh@email.arizona.edu \\ * Corresponding author
}

Published: 9 January 2008

BMC Evolutionary Biology 2008, 8:3 doi: |0.1 |86/147|-2/48-8-3

This article is available from: http://www.biomedcentral.com/I47I-2/48/8/3

(C) 2008 Badyaev and Oh; licensee BioMed Central Ltd.

This is an Open Access article distributed under the terms of the Creative Commons Attribution License (http://creativecommons.org/licenses/by/2.0), which permits unrestricted use, distribution, and reproduction in any medium, provided the original work is properly cited.
Received: 8 June 2007

Accepted: 9 January 2008

\begin{abstract}
Background: The origin of complex adaptations is one of the most controversial questions in biology. Environmental induction of novel phenotypes, where phenotypic retention of adaptive developmental variation is enabled by organismal complexity and homeostasis, can be a starting point in the evolution of some adaptations, but empirical examples are rare. Comparisons of populations that differ in historical recurrence of environmental induction can offer insight into its evolutionary significance, and recent colonization of North America by the house finch (Carpodacus mexicanus) provides such an opportunity.
\end{abstract}

Results: In both native (southern Arizona) and newly established (northern Montana, 18 generations) populations, breeding female finches exhibit the same complex adaptation - a sex-bias in ovulation sequence - in response to population-specific environmental stimulus of differing recurrence. We document that, in the new population, the adaptation is induced by a novel environment during females' first breeding and is subsequently retained across breeding attempts. In the native population, first-breeding females expressed a precise adaptive response to a recurrent environmental stimulus without environmental induction. We document strong selection on environmental cue recognition in both populations and find that rearrangement of the same proximate mechanism - clustering of oocytes that become males and females - can enable an adaptive response to distinct environmental stimuli.

Conclusion: The results show that developmental plasticity induced by novel environmental conditions confers significant fitness advantages to both maternal and offspring generations and might play an important role not only in the successful establishment of this invasive species across the widest ecological range of extant birds, but also can link environmental induction and genetic inheritance in the evolution of novel adaptations.

\section{Background}

Evolutionary biology is concerned with explaining the origin and diversification of organismal forms. However, despite great advances in the understanding of maintenance and adaptive evolution of existing organismal forms, we still know very little about their origin $[1,2]$.
Especially puzzling is the origin of complex adaptations that involve close and context-dependent integration of multiple organismal systems.

The dual effect of a novel environment on phenotypic plasticity - simultaneous exposure of "hidden" develop- 
mental variation and strong selection on this variation can be a starting point in the evolutionary persistence of some adaptations [3-6]. When individuals vary in their response to the novel stimulus, when this variability is heritable, and the stimulus is recurrent, such environmental induction can lead to eventual genetic determination of a novel adaptation $[7,8]$. The central thesis of this view is that evolutionary novelty often involves reorganization of preexisting phenotypes $[9,10]$ and this results in similarity of the novel changes among individuals, facilitates response to novel selection pressures, and can ultimately lead to genetic assimilation of the novel trait [9,11-16]. Yet, empirical documentation of evolutionary persistence of environmentally induced adaptations is rare in natural populations [17-19].

Documentation of environmental induction and phenotypic retention of adaptive plasticity is the first step in investigating this proposed sequence, and rapid colonization of North America in the last 70 years by the house finch (Carpodacus mexicanus) - a species native to southwestern United States - provides such an opportunity. In both native (southern Arizona) and newly established (northern Montana) populations, sex-bias in ovulation sequence (Figure 1) confers significant fitness benefits - in the recently established population, it increases phenotypic variance in offspring growth which leads to greater juvenile survival under novel ecological conditions, and in the native population, it lessens offspring exposure to ectoparasites and associated mortality [20-22]. In Montana, the environmental stimulus to sex-biased ovulation is closely associated with the number of days during oogenesis when the ambient temperature falls below $4^{\circ} \mathrm{C}-$ minimum egg-tolerance temperature for most passerine birds ("critical temperature days" hereafter; [23]). In the native population in Arizona, the environmental cue is exposure of females during egg-laying to hematophagous ectoparasitic nest mite Pellonyssus reedi that infests most nests for 1.5-2 months during the late part of each breeding season [21]. The cues are unique for each population - Montana population is not exposed to nest mites, whereas Arizona population is not exposed to below eggtolerance temperature during oogenesis and egg-laying.

Here we studied the similarity in responses to populationspecific environmental stimulus and proximate mechanisms behind such responses in first-breeding (i.e., 8-12 months old) females in each population. Because most first-breeding females in the recently-established Montana population are long-distance immigrants from southern populations [24], they are not expected to have either an evolved recognition of the local environmental stimulus at the northernmost part of the species' range or an evolved and precise modification of ovulation
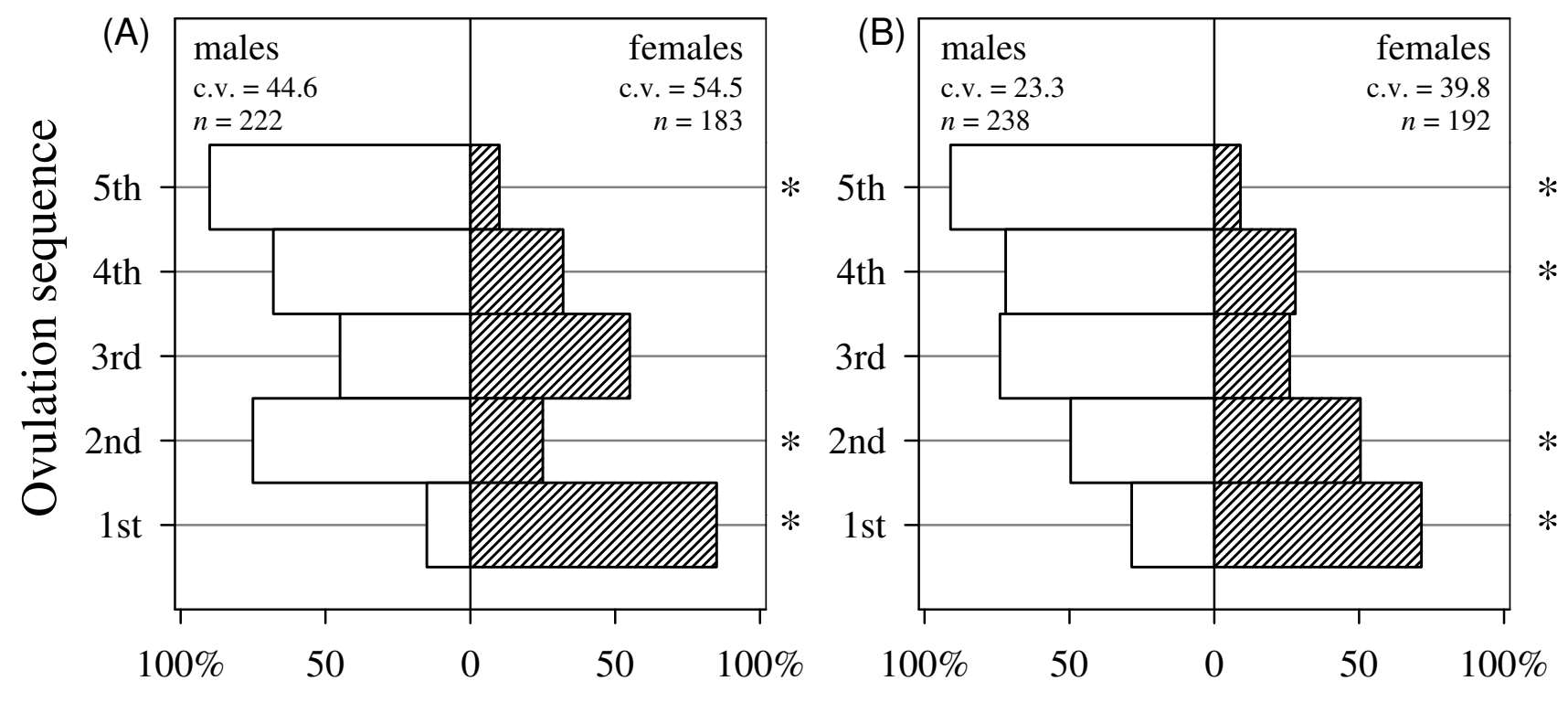

Figure I

Short-term sex-bias in ovulation sequence in house finch females. Sex-bias in response to $A$ ) ambient temperature below egg-viability threshold during early breeding season in Montana ( $n=86$ nests), and B) late season nest mite infestation in Arizona ( $\mathrm{n}=110$ nests). In both populations, there was no sex-bias in ovulation sequence in other parts of the breeding season. Asterisks show sex-ratios significantly deviating from parity. Coefficient of variation (cv) indicates variability in relative ovulation sequence of male and female eggs (see Methods). 
sequence in response to this stimulus. On the other hand, first-breeding females in the Arizona population are mostly locally born or short-distance immigrants from local populations that experience yearly seasonal mite infestation that exerts high nestling mortality [21], and thus are expected to have evolved both a recognition of the local environmental stimulus (onset of mite season) and a response to it.

\section{Results}

\section{Response to environmental stimulus}

Sex-bias in ovulation sequence of first-breeding females was closely associated with the number of critical temperature days during oogenesis in Montana (MT hereafter; maximum likelihood estimation $\chi^{2}=45.28, p<0.001$ ) and with number of mites at the nest site in Arizona (AZ hereafter; $\left.\chi^{2}=106.3, p<0.001\right)$, but the shape of the relationship differed between the populations. Linear regression best described the relationship between the response and stimulus for first-breeding females in MT (Figure 2a; biases $=0.93 \pm 0.12$ (s.e.m.) $+0.22 \pm 0.02$ critical days, $t$ $=9.64, \mathrm{n}=93, p<0.001$; cubic spline fit versus linear regression fit: $\mathrm{t}=4.66, p<0.01$ ), whereas a threshold-like cubic spline best described the relationship in first-breeding females in AZ (Figure $2 \mathrm{~b}, \chi^{2}=25.3, \mathrm{n}=131, p<0.01$ ). First-breeding females in MT had less precise sex-bias of ovulation sequence than first-breeding females in AZ (Figure 1; CV of within-sex variability of ovulation positions - males: $44.6 \%$ (MT) vs. $23.3 \%$ (AZ), females: 54.5 vs. $39.8 \%$; both Fs $>3.38, p<0.05)$.

Covariation between sex-bias and environmental stimulus across breeding episodes differed between the populations (Figure 2cd; interaction: population $\mathrm{x}$ breeding episode $x$ relative stimulus, $\left.F_{1,243}=5.98, p=0.015\right)$. In MT, threshold for environmental induction of sex-bias decreased across breeding episodes in females that were followed throughout their lifetime (Figure $2 \mathrm{c} ; \chi^{2}=8.05, \mathrm{n}$ $=51, p=0.01)$, and by the third breeding episode a single critical temperature day during oogenesis was sufficient to exert a full response (Figure 2c). However, the strength of the response did not differ across breeding episodes across females' lifetime (Figure $2 \mathrm{e} ; \chi^{2}=4.33, p=0.12$ ). In $\mathrm{AZ}$, neither the relationship between cue and response (Figure $2 \mathrm{~d} ; \chi^{2}=0.84, \mathrm{n}=29, p=0.51$ ), nor the strength of the response differed across breeding episodes (Figure $2 \mathrm{f} ; \chi^{2}=$ $3.54, p=0.14)$.

\section{Natural selection on response to environmental stimulus}

We documented strong selection on response to environmental stimuli in both populations (Figure 3). In MT, first-breeding females that biased ovulation order when experiencing critical temperature days during oogenesis had the highest fledging success, whereas females that experienced the critical temperature days but did not bias ovulation sequence had the lowest success (Figure 3a; standardized selection differentials: $\mathrm{b}_{\mathrm{ST}}$ (bias) $=0.43, \mathrm{t}=$ $5.25, p<0.01 ; \mathrm{b}_{\mathrm{ST}}$ (stimulus) $\left.=-0.13, \mathrm{t}=-1.46, \mathrm{~ns}\right)$. In $\mathrm{AZ}$, first-breeding females that responded strongly to the mites had the highest fledging success, whereas females that had lesser or no response had the lowest success (Figure $3 \mathrm{~b} ; \mathrm{b}_{\mathrm{ST}}$ (bias) $=0.42, \mathrm{t}=6.21, p<0.01, \mathrm{~b}_{\mathrm{ST}}$ (stimulus) $=-0.39, \mathrm{t}=-5.82, p<0.01)$. The strength of selection on response to stimulus differed between the populations (interaction: population $\mathrm{x}$ relative stimulus $\mathrm{x}$ response: $\mathrm{F}_{1,223}=56.15, p<0.001$, interaction: cue $\mathrm{x}$ population: $\mathrm{F}_{1,223}=27.51, p<0.001 ;$ model $\left.\mathrm{F}_{7,223}=25.01, p<0.01\right)$, however the sharper peak of the estimated AZ fitness contour was likely confounded by the direct mortality effect of nest mites on nestling survival in nests with more than 20 mites at the onset of incubation (Figure 3b).

\section{Proximate mechanisms of response to environmental cue}

To investigate the proximate mechanisms behind adaptive sex-biased ovulation, we studied similarity in yolk uptake among oocytes within and between sexes within a clutch in both populations. Specifically we examined whether oocytes that become males and females were recruited into the rapid growth stage at different times during oogenesis (see Background to avian oogenesis below; Figure $4 \mathrm{a}, \mathrm{c}$ ), a pattern expected to generate stronger correlations of yolk partitioning among singlesex follicles compared to mixed-sex follicles, or whether male and female oocytes are recruited in random order (Figure 4bd), a pattern not expected to generate sex-specific groups of oocytes similar in yolk deposition [see [25] for details]. In first-breeding females in AZ, our analyses revealed three significantly different, mostly sex-specific, oocyte groups in females that experienced mite infestation and had sex-biased ovulation order (Figure $4 \mathrm{a}$; pseudo- $\mathrm{t}^{2}$ $=10.01, p<0.001)$, and three weakly differentiated, mixed-sex groups in females that breed under mite-free conditions and did not bias ovulation order (Figure 4b; pseudo $\mathrm{t}^{2}=5.76, p<0.05$; difference: Wilks' $8=0.91, \mathrm{~F}=$ $3.06, p<0.05)$. In MT, there were four sex-specific groups in females that experienced critical temperature days during oogenesis (pseudo- $\mathrm{t}^{2}=29.5, p<0.05$ ), and two weakly differentiated, mixed-sex groups in females that did not experience critical temperature days during oogenesis (pseudo- $\mathrm{t}^{2}=8.3, p<0.05$; difference: Wilks' $8=1.16, \mathrm{~F}=$ $4.36, p<0.05)$.

\section{Discussion}

In order for environmentally-induced plasticity to have long-term evolutionary consequences, it has to be allowed and retained by organismal homeostatic processes, have a heritable component, induce similar changes across individuals, and confer consistent fitness benefits $[6,9,26]$; however, studies of these requirements are rare in natural systems. In several populations of house finches across 

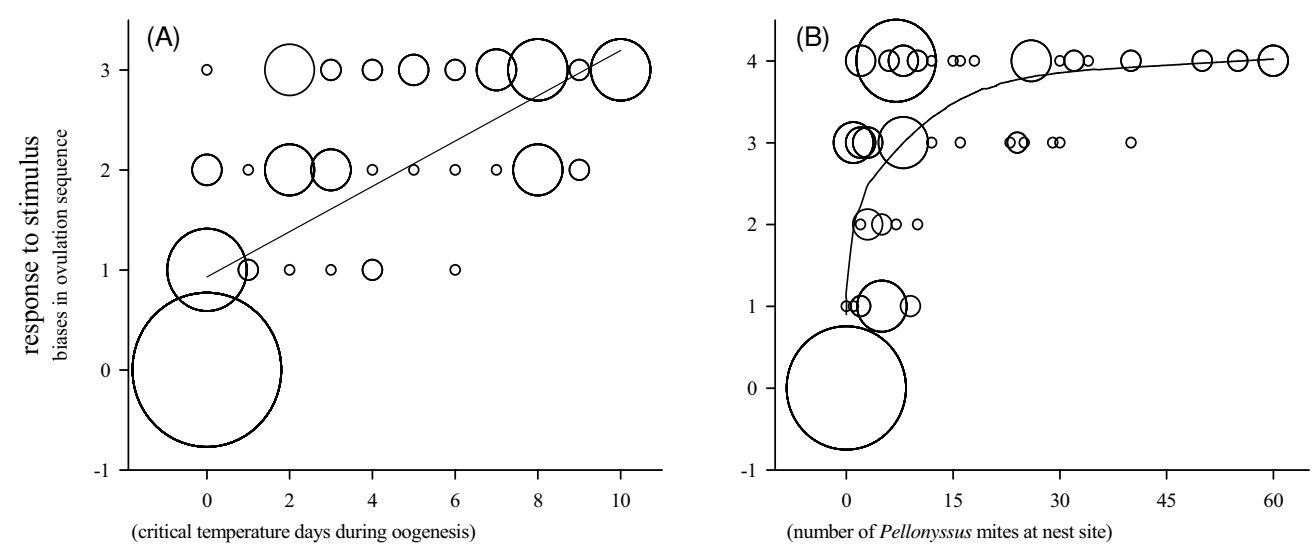

environmental stimulus
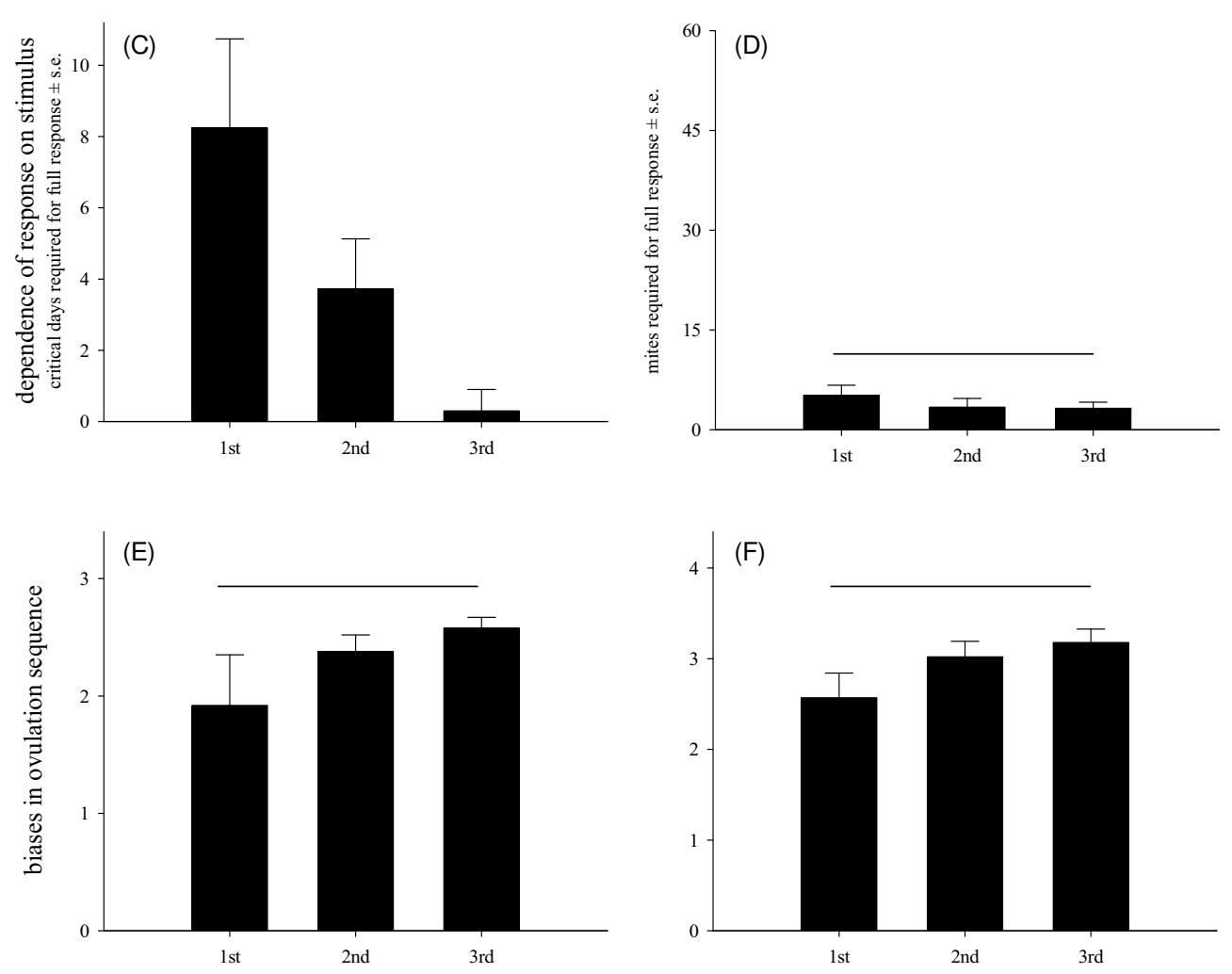

breeding episodes, years

\section{Figure 2}

The relationship between environmental stimulus (critical temperature days during oogenesis in Montana and number of mites at nest sites in Arizona) and response to the stimulus (number of biases in ovulation sequence) in A) first-breeding females in Montana ( $n=93$ females), B) first-breeding females in Arizona ( $n=|3|$ females). C) Estimated number (mean \pm s.e.m.) of critical temperature days during oogenesis required to exert full response (three biases in ovulation sequence) across female's lifetime in Montana ( $n=51$ females), D) Estimated number (mean \pm s.e.m.) of nest mites during oogenesis required to exert full response (four biases in ovulation sequence) across female lifetime in Arizona ( $n=29$ females). Note that the ordinate axes in C) and D) are scaled identically to the abscissa axes in $\mathbf{A}$ ) and B) to show the full range of the stimulus. E) Biases (mean deviations \pm s.e.m.) in ovulation sequence across three breeding episodes of the same females in Montana, and F) in Arizona. Bubble radius is proportional to the number of overlapping data points. Lines connect means that are not significantly different. 
(A)

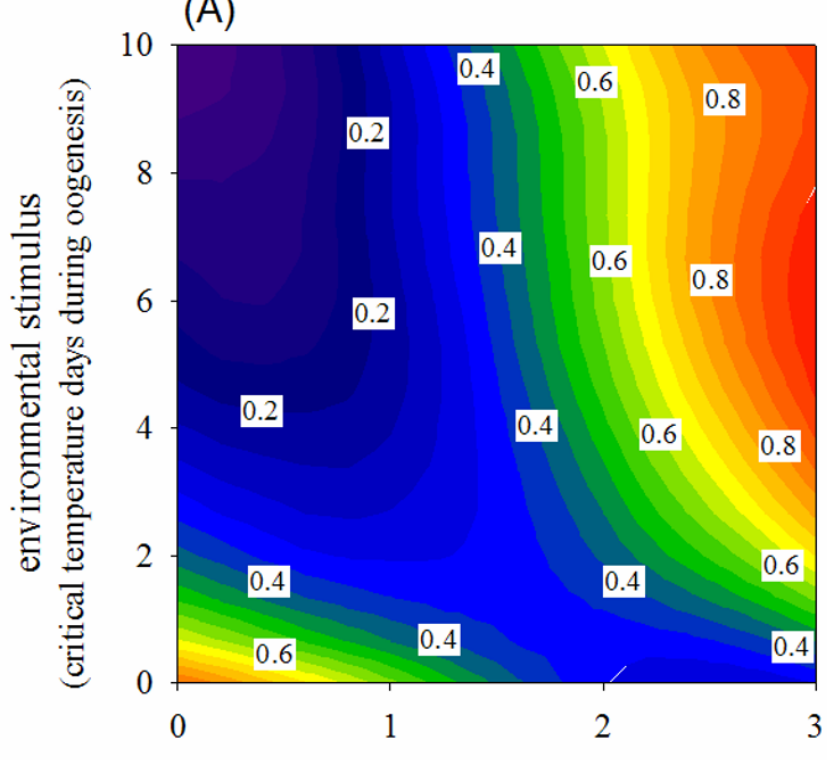

(B)

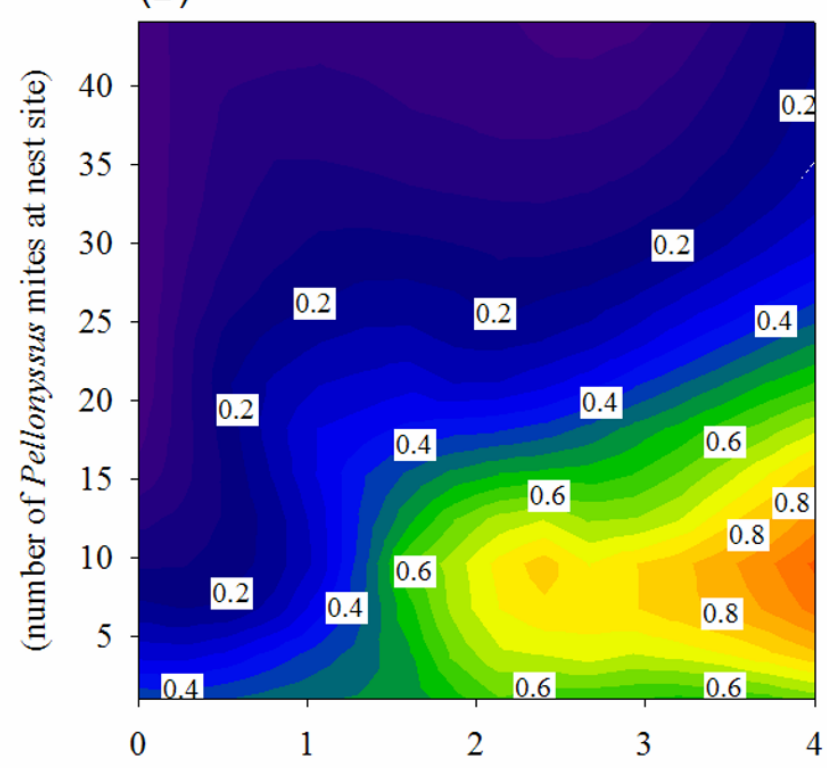

response to environmental stimulus

(biases in ovulation sequence)

\section{Figure 3}

Estimated contour plots of offspring survival as a function of number of deviations (biases) in ovulation sequence. Response to $\mathbf{A}$ ) critical temperature days in Montana population ( $\mathrm{n}=128$ nests), and $\mathbf{B}$ ) number of mites at nest site in Arizona population ( $n=96$ nests infested with mites). Note that the ordinate axis shows number of mites at the stage of egg-laying and this number increases greatly by the time nestlings hatch and mite-induced mortality occurs. Numbers show proportion of nestlings fledged out of the number of eggs laid.

North America, modification of within-clutch laying sequence of male and female eggs is under current natural selection in both maternal and offspring generations; these modifications are thought to be proximately produced by interplay of induced changes in maternal hormonal profile during breeding in novel or stressful conditions and associated distinct accumulation of hormones by oocytes that become males or females [23,27]. Here we showed that, first, the sex-biased ovulation sequence in first-breeding females in the newly established population was induced approximately proportionally to novel environmental stimulus, whereas firstbreeding females in the native population responded to the environmental stimulus in a precise threshold-like pattern and without induction (Figure 2). Second, the dependence of response on environmental stimulus lessened across a females' lifetime in the newly established population (Figure 2c). Third, in both populations, sexbiased ovulation order was associated with the same mechanism - sex-specific groups of oocytes most likely induced through temporal similarity in recruitment time between oocytes that become the same sex (Figure 4; [25]).
These results raise two main questions. First, what are the mechanisms enabling phenotypic accommodation of environmentally-induced response across a female's lifetime? Second, how can environmental induction of ovulation sequence lead to evolution of precise patterns of sex-biased ovulation sequence found in some birds, including in the ancestral population of the study species? We also discuss alternative explanations for the observed findings, including the evolution of reaction norms in maternal traits between populations.

In both populations, the response to distinct environmental cues was produced by rearrangement of the same proximate mechanism - clustering of male and female oocytes. We suggest that such clustering is induced by temporal hormonal fluctuations in female's plasma, such that the effect of ambient temperature on prolactin-regulated female's incubation behaviors or direct experience of nest mites at the onset of mite infestation season, induces female hormonal fluctuations, resulting in exposure of growing oocytes to distinct hormonal profiles, subsequent accumulation of distinct hormonal concentrations which in turn, can affect the sex-determining meiotic divi- 
(A)
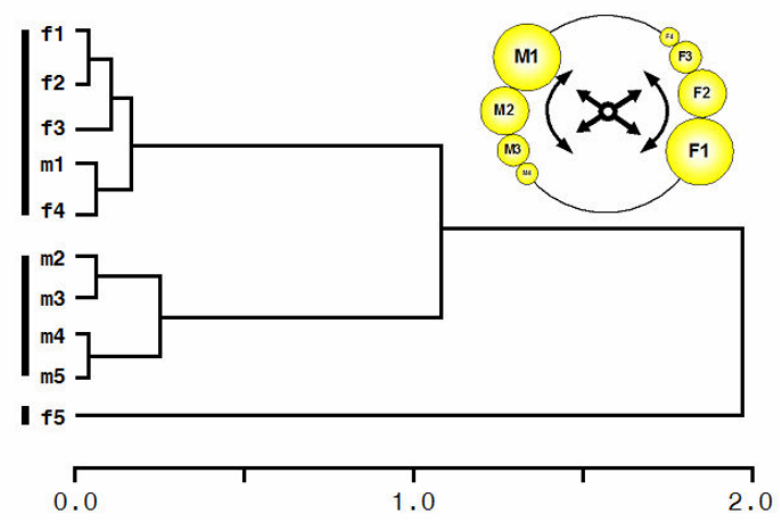

(C)
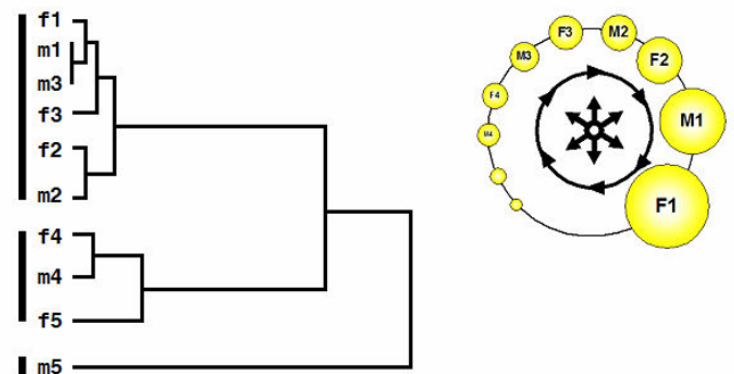

(B)

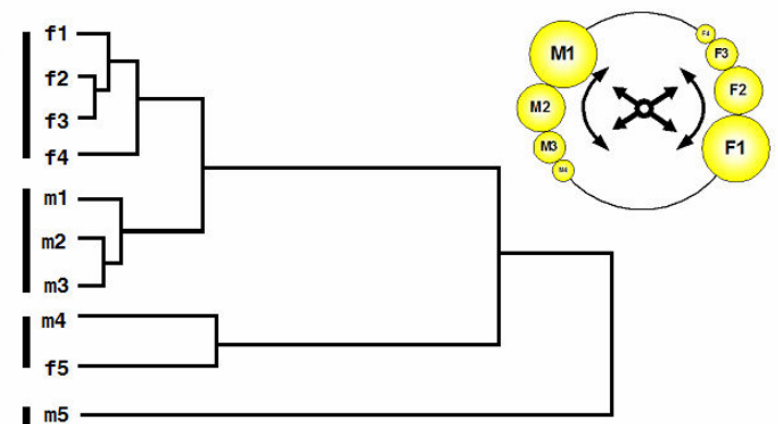

(D)
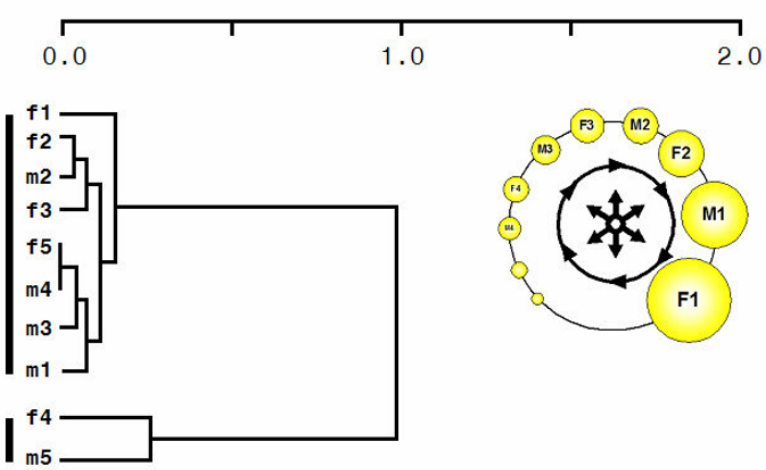

Figure 4

Groups of oocytes similar in yolk (x-axis - Ward's minimum distance) in relation to oocyte' sex and ovulation order in first-breeding females. A) Arizona population under mite infestation conditions ( $n=72$ nests), B) Montana population with $>5$ critical days during oogenesis ( $n=63$ nests), C) Arizona population under mite free conditions $(n=99$ nests), D) Montana population with $\leq \mathrm{I}$ critical days during oogenesis $(n=34$ nests). Drawings show hypothetical arrangement of oocytes in the ovary that would correspond to sex-specific clusters in A) and B) or non-sex specific hierarchical arrangement in $\mathbf{C}$ ) and $\mathbf{D})$. Vertical bars on the left side delineate significantly distinct clusters.

sion of oocytes [25,27-29]. Indeed, because hormonal mechanisms are involved in both assessment of environmental change and incorporation of novel environmental input, environmental induction of hormonal changes and subsequent phenotypic retention of their effects is a frequently documented route in the evolution of novel adaptations and morphologies [8,30-33]. Because of its complexity, redundancy, and environmental sensitivity, hormonal regulation of avian reproductive system is particularly well-suited for retention of environmentallyinduced modifications [34]. Specifically, hormones regulating oocyte proliferation and ovulation have strong environmental sensitivity, and hormonally-mediated changes in gene expression as a result of prior breeding experience, changes in photoperiod, food, mate familiarity, or ambient temperature are often documented [3539]. Moreover, environmental modifications of the first ovulation sequence, such as sensitivity to ovulationinducing hormones, might be retained throughout a female's lifetime in vertebrates [40-42], apparently by the homeostatic effects of complex reproductive systems. Thus, hormonal regulation might have a major role in the observed rearranging the same mechanism for novel inputs and novel functions in the two study populations.

Female birds can show precise and context-dependent adjustment of sex-bias in laying order in relation to changes in mate quality, food availability, and time of breeding season, both across individuals [43-46] and between breeding attempts [47-49]. How can precise sexbias in ovulation sequence evolve, especially when its initial induction is likely to be imprecise (e. g., Figures 1a, $2 e)$ ? We propose that evolved precision in sex-bias is caused by the linkage between hormonal mechanisms that influence sex-determination and mechanisms that enable distinct accumulation of hormones in oocytes that become males and females. Distinct allocation of hormones into male and female oocytes is under strong selection on offspring growth; for example in the two recently established house finch populations with opposite sexbias in ovulation sequence, males produced in femalebiased positions and females in male-biased positions accumulated hormones incompatible with their normal development [50], likely accounting for strong selection 
for environmental stimulus recognition documented in this study (Figure 3a). Because hormones in female plasma change with the progress of oogenesis, laying, and incubation, oocytes develop in and accumulate different hormonal milieus depending on the time of their sequestration, which, in turn, might produce temporal bias in time of sequestering of oocytes that become males and females resulting in sex-specific groups of oocytes described here [see also [51-53]]. Thus, natural selection should maintain close integration between the mechanisms by which hormones can bias sex-determination (including through environmental induction) and mechanisms enabling sex-specific accumulation of hormones by oocytes. Such integration not only can explain the observed within-generation increase in precision of sexbias in ovulation sequence (Figure 2e), but also might be the mechanism for precise sex-specific maternal allocation of resources within a clutch in some birds [54-56].

In the native population, the finding of higher precision, greater expression, and lesser dependency of sex-bias in ovulation sequence on environmental induction (Figure $1,2 d$ ) is consistent with observations that sex-bias in ovulation is accompanied by precise maternal adjustment of offspring growth, likely representing an evolved motheroffspring co-adaptation under selection on offspring morphology during periodic mite infestation [21]. On the contrary, in the new population, selection on modification of ovulation sequence acted primarily on the maternal generation, such that females that were able to resolve the contrasting hormonal requirements of overlapping incubation and oogenesis under novel breeding conditions had the highest fitness [23]. Elsewhere, we analyzed the effects of maternal adaptation on offspring across ten consecutive generations in relation to similarity in environmental conditions between maternal and offspring generations and found that the effects of induced maternal adaptation on the offspring induced wider phenotypic plasticity in offspring development and morphology rather than precise adjustment of offspring growth [22].

Alternatively, the newly established population might be expressing only a variant of the reaction norm that cannot be expressed in the native population due to more consistent and stronger selection on the reaction norm there [5759]. In the context of this study system, the reaction norm is the sensitivity to environmental stimuli or a narrower range of adaptive response in the native population. However, strong within-individual changes in phenotypic plasticity (Figure 2c), the precise and complex nature of adaptive response where a different sex-bias in ovulation sequence is favored in different populations (Figure 1), and the fact that stimuli are unique for each population make it unlikely that the observed population differences in dependence of the response on the stimulus (Figure 2c, d) constitute differential expression of the same reaction norm or a retained response. At the same time, it is important for future studies to address the within-population contribution of genetic and environmental factors to the evolution of reaction norms.

\section{Conclusion}

Across dispersing and native populations of the house finch, we observe differential importance of maternal effects for the evolution of local adaptations - from environmentally-induced maternal effects that increase developmental plasticity in the first few generations of the newly established population to the reliable production of locally adaptive morphologies in the absence of sexbiased maternal effects, but short-term and reversible maternal effects on offspring growth under mite infestation in the native population [20-22]. We showed that developmental plasticity induced by novel environmental conditions confers significant fitness advantages to both maternal and offspring generations and might play an important role not only in the successful establishment of house finches across the widest ecological range of extant bird species, but also can provide an example of the link between environmental induction and genetic inheritance in the evolution of novel adaptations.

\section{Methods \\ Study populations and general methods}

House finches were studied in 1995-2006 in the recently established population at the northernmost part of species' range in northwestern Montana, where this species started breeding in the late 1970s, and in 2002-2007 in the southern part of their native range in southwestern Arizona, $2700 \mathrm{~km}$ to the south, where finches bred for at least 10,000 years. In both populations, all resident birds were marked with a unique combination of four rings, and age category and prior breeding experience were known for all birds included in this study. All females laid one egg per day between 0500 and 1100 and eggs were numbered sequentially on the day of laying. Embryos or nestlings were sexed molecularly [60] and the maximum oogenesis duration (ten days concluding with the laying of penultimate egg and ovulation of the last egg) was assessed with the oocyte lipid accumulation method [61]. To minimize the effect of clutch size on sex-bias in ovulation sequence, we restricted the analyses to 4 and 5 egg clutches. Analysis of similarity of oocyte yolk uptake was conducted according to [[25], see also below]. To examine changes in response across breeding attempts we followed the same females across their lifetime.

\section{Environmental stimulus and response measures}

In the MT population, we recorded the number of days during a ten-day oogenesis period with average daily ( 24 hr) temperature $\leq 4{ }^{\circ} \mathrm{C}$ ("critical temperature days"). To 
minimize the effect of timing of this environmental stimulus on probability of response, we excluded four nests where the stimulus was absent during the first five days of oogenesis. Weather data were obtained from permanent weather stations at the Missoula Country Airport one km from the MT study site [28]. In Arizona population, we counted Pellonyssus reedi mites at nest sites every second day and the total population of mites was subsequently verified by fumigating nests with chloroform; only estimated abundance of nest mites at the egg-laying stage was used in this study. Because the full adaptive response population-specific ovulation sequences of male and female eggs - was known for each population ([20,21], which see for tests of sex-biased ovulation), we measured the magnitude of the response as the number of "correct" deviations in each ovulation sequence (i.e., clutch) following [23]. Briefly, full "correct" response was three positions deviated from parity $\left(1^{\text {st }}, 2^{\text {nd }}\right.$, and the last $)$ for the MT population and four deviated positions $\left(1^{\text {st }}, 2^{\text {nd }}, 4^{\text {th }}\right.$ and last) for the AZ population (Figure 1). To compare populations, we divided the number of deviations ("biases" hereafter) for each female by the maximum number of deviations for the population. All analyses involving this measure were conducted with nest identity as a random effect to correct for female-specific ovulation sequences. Variability in the precision of sex bias in ovulation sequences (Figure 1) was measured by ranking male and female egg-laying positions separately within a clutch and calculating coefficient of variation for mean within-clutch probability position for each sex [see also [62]] that was subsequently compared with Levene's test.

\section{Brief background to avian oogenesis}

Ovarian oocytes recruited into the pre-ovulatory pool undergo rapid yolk accumulation and typically form temporal hierarchy of growth, followed by sequential ovulation. In addition to temporal variation in recruitment to the rapid yolk deposition stage, hierarchical arrangements among the simultaneously growing oocytes and ovulation intervals are maintained by growth inhibiting hormonal interactions among maturing oocytes [63-65]. Such inhibiting interactions have pronounced spatial patterns, such that only follicles in the close proximity or at similar stages of development are affected. Thus, differences between oocytes that become males and females in either time of recruitment or in spatial arrangement in the ovary can produce sex-specific groups or "clusters" of oocytes. Such clusters have been inferred through analyses of similarity in oocyte accumulation of lipids, carotenoids, vitamins, and hormones $[25,27,50]$.

\section{Statistical analyses}

To assess shape and magnitude of the response (e.g., bias number) as a function of environmental stimulus (number of critical days in MT and number of mites at nest site in AZ) we used regression procedures in generalized additive models of PROC GAM in SAS 9.13. The Poisson regression analysis of GAM procedure enables simultaneous test of the stimulus, estimation and statistical comparison of the best shape of the relationship between the stimulus and the response, and visual assessment of the value of stimulus corresponding with the full response. To estimate and test the change in dependency of the response on stimulus, we plotted, with ODS graphics module of PROC GAM, for each breeding episode in both populations, the $99 \%$ confidence interval around the best-fit curve. We then recorded the smallest value of the stimulus corresponding to the full response (three positions in MT and four in AZ). We repeated this procedure with replacement for all nests in MT and AZ datasets and mean \pm s.e.m. were calculated for Figure $2 c$, d. Overall significance of the dependency of response on stimulus was tested with PROC GENMOD logistic regression, the means of response dependence on stimulus among breeding episodes were compared with Waller-Duncan K-ratio $t$-test, and the magnitude of response across breeding episodes was compared with repeated measures ANOVA in REPEATED module of PROC MIXED of SAS 9.13 with breeding episode, female age cohort, and year as categorical fixed effects and female identity as a random effect. To compare response to environmental stimulus across all females, breeding episodes, and populations in the single test, we standardized both the response and strength of stimulus variables to percentages of the full response and maximum stimulus (three biased positions, and 10 critical temperature days in MT and four biased positions and 55 mites in AZ) and tested the interaction between the factors with PROC GLM with the response constrained by female identity. Correlational structure of oocyte similarity in yolk uptake was converted to distances in canonical discriminant analysis (PROC CANDISC in SAS 9.13). The cluster analysis of similarity in correlational structure between follicles of different ovulation order and sex was conducted by Ward's minimum distance method using pseudo- $F$ and preudo- $t^{2}$ statistics to estimate the number of statistically distinct clusters [after [25]].

\section{Authors' contributions}

AVB designed the study and wrote the manuscript. AVB and KPO conducted field work and analyzed the data. Both authors read and approved the manuscript.

\section{Acknowledgements}

We thank R. Duckworth, E. Landeen, J. Rutkowska, R. Young and three reviewers for very helpful comments and suggestions on previous versions of this manuscript, many assistants for help in the field at both study sites, E. Lindstedt, K. Soetaert, C. Secomb, and J. Hubbard for molecular sexing analyses, R. Young and D. Seaman for measuring oocyte growth, T. Hamstra for conducting nest fumigation for mites, and R. McCue and the personnel of the Vigilante MiniStorage of Missoula, Montana for allowing us to work on their property for the last twelve years. This work was supported 
by grants from the National Science Foundation and by the David and Lucille Packard Fellowship.

\section{References}

I. Lewontin RC: Gene, organism and environment. In Evolution From Molecules to Men Edited by: Bendall DS. Cambridge: Cambridge University Press; 1983:273-285.

2. Müller GB, Newman S: Origination of organismal form: Beyond the gene in developmental and evolutionary biology. Cambridge: The MIT Press; 2003.

3. Baldwin JM: A new factor in evolution. American Naturalist I896, 30:44I-45I.

4. Schmalhausen II: Factors of evolution Philadelphia, Pennsylvania: Blakiston; 1949.

5. Eshel I, Matessi C: Canalization, genetic assimilation and preadaptation: A quantitative genetic model. Genetics 1998, 149:2119-2133.

6. Jablonka E, Lachmann M, Lamb MJ: Evidence, mechanisms and modelsfor the inheritance of acquired characters. J theor Biol 1992, I 58:245-268.

7. Waddington $\mathrm{CH}$ : Canalization of development and genetic assimilation of acquired characters. Nature 1959, I 83:1654-1655.

8. West-Eberhard MJ: Developmental Plasticity and Evolution. Oxford:Oxford University Press; 2003.

9. West-Eberhard MJ: Phenotypic accommodation: adaptive innovation due to developmental plasticity. Journal of Experimental Zoology(Mol Dev Evol) 2005, 304B:6I0-6I8.

10. Rollo D: Phenotypes: Their Epigenetics, Ecology, and Evolution. London: Chapman and Hall; 1994.

II. Schlichting CD, Pigliucci M: Phenotypic evolution: A reaction norm perspective. Sinauer Associates; 1998.

12. Pigliucci M, Murren CJ, Schlichting CD: Phenotypic plasticity and evolution by genetic assimilation. Journal of Experimental Biology 2006, 209:2362-2367.

13. Pigliucci M, Murren CJ: Genetic assimilation and a possible evolutionary paradox: Can macroevolution sometimes be so fast as to pass us by? Evolution 2003, 57:|455-|464.

14. Nanjundiah V: Phenotypic plasticity and evolution by genetic assimilation. In Origination of Organismal Form: beyond the gene indevelopmental and evolutionary biology Edited by: Muller GB, Newman S. Cambridge: The MIT Press; 2003:245-263.

15. Badyaev AV: Stress-induced variation in evolution: from behavioral plasticity to genetic assimilation. Proceedings of Royal Society London: Biological Sciences 2005, 272:877-886.

16. Young RL, Badyaev AV: Evolution of ontogeny: linking epigenetic remodeling and genetic adaptation in skeletal structures. Integrative and Comparative Biology 2007, 47:234-244.

17. Brylski P, Hall BK: Ontogeny of a macroevolutionary phenotype:the external cheek pouches of Geomyoid rodents. Evolution 1988, 42:391-395.

18. Palmer AR: Symmetry breaking and the evolution of development. Science 2004, 306:828-833.

19. Heil M, Greiner S, Meimberg H, Kruger R, Noyer J-L, Heubl G, Linsenmair KE, Boland W: Evolutionary change from induced to constitutive expression of an indirect plant resistance. Nature 2004, 430:205-208.

20. Badyaev AV, Hill GE, Beck ML, Dervan AA, Duckworth RA, McGraw KJ, Nolan PM, Whittingham LA: Sex-biased hatching order and adaptive population divergence in a passerine bird. Science 2002, 295:316-318.

21. Badyaev AV, Hamstra TL, Oh KP, Acevedo Seaman D: Sex-biased maternal effects reduce ectoparasite-induced mortality in a passerine bird. Proceedings of the National Academy of Sciences of the United Statesof America 2006, I 03: I 4406-I44III.

22. Badyaev AV: Maternal inheritance and rapid evolution of sexualsize dimorphism: Passive effects or active strategies? American Naturalist 2005, I66:SI7-S30.

23. Badyaev AV, Schwabl H, Young RL, Duckworth RA, Navara K, Parlow AF: Adaptive sex differences in growth of pre-ovulation oocytes in apasserine bird. Proceedings of the Royal Society Biological Sciences Series B 2005, 272(I 577):2165-2I72.

24. Oh KP, Badyaev AV: Adaptive genetic complementarity coexists with selection for elaborate sexual traits in mate choice of a passerine bird. Proceedings of Royal Society London: Biological Sciences 2006, 273:1913-1919.

25. Badyaev AV, Oh KP, Mui R: Evolution of sex-biased maternal effects in birds: II. Contrasting sex-specific oocyte competition in nativeand recently established populations. Journal of Evolutionary Biology 2006, 19:909-921.

26. Waddington $\mathrm{CH}$ : Genetic assimilation. Advances in Genetics I96I, I 0:257-290.

27. Badyaev AV, Young RL, Hill GE, Duckworth RA: Evolution of sexbiased maternal effects in birds: IV. Intra-ovarian growth dynamics canlink sex-determination and sex-specific acquisition of resources. Journal of evolutionary biology 2008. doi: I0.1 I I I/ j.1420-9101.2007.01498

28. Badyaev AV, Beck ML, Hill GE, Whittingham LA: The evolution of sexual size dimorphism in the house finch: $V$. Maternal effects. Evolution 2003, 57:384-396.

29. Rutkowska J, Badyaev AV: Meiotic drive and sex determination: Molecular mechanisms of sex ratio adjustment in birds. Phil Trans RSoc Lond B 2007.

30. Guerrero-Bosagna C, Sabat P, Valladares L: Environmental signaling and evolutionary change: can exposure of pregnant mammals to environmental estrogens lead to epigenetically induced evolutionary changesin embryos? Evolution and Development 2005, 7:34I-350.

31. Weaver ICG, Cervoni N, Champagne FA, D'Alessio AC, Sharma S, Seckl JR, Dymov S, Szyf M, Meaney MJ: Epigenetic programming by maternal behavior. Nature Neuroscience 2004, 7:847-854.

32. Suzuki Y, Nijhout HF: Evolution of a polyphenism by genetic accommodation. Science 2006, 31 I:650-652.

33. Cremer S, Heinze J: Stress grows wings: environmental induction of winged dispersal males in Cardiocondyla ants. Current Biology 2003, I 3:21 9-223.

34. Johnson AL: Reproduction in the female. In Sturkie's Avian Physiology 5 th edition. Edited by: Whittow GC. San Diego: Academic Press; 2000:569-596.

35. Sockman KW, Sharp PJ, Schwabl H: Orchestration of avian reproductive effort: an integration of the ultimate and proximate bases for flexibility of clutch size, incubation behavior, and yolk-androgen deposition. Biological Reviews 2006, 8 I :629-666.

36. Sockman KW, Williams TD, Dawson A, Ball GF: Prior experience with photostimulation enhances photo-induced reproductive development infemale European starlings: a possible basis for the age-related increase inavian reproductive performance. Biology of Reproduction 2004, 71 :979-986.

37. Pike TW, Petrie M: Experimental evidence that corticosterone affects offspring sex ratios in quail. Proc $R$ Soc Lond B 2006, 273:1093-1098.

38. Cheng M-F: Female cooing promotes ovarian development in Ring Doves. Physiology and Behavior 1986, 37:371-374.

39. Adkins-Regan E, Ottinger MA, Park J: Maternal transfer of estradiol to egg yolk alters sexual differentiation of avian offspring. Journal of Experimental Zoology 1995, 27 I:466-470.

40. Fukuda M, Fukuda K, Andersen CY, Byskov AG: Right-sided ovulation favours pregnancy more than left-sided ovulation. Human Reproduction 2000, I 5(9): 1921-1926.

4I. Yoo BH, Sheldon BL, Podger RN: Analyses of oviposition times and intervals in a wide range of layer flocks under normal and continuous lighting regimes. British Poultry Science 1986, 27:267-288.

42. Bhatti BM, Morris TR: The relative importance of sunrise and sunset for entrainment of oviposition in the fowl. British Poultry Science 1978, 19:365-37|.

43. Andersson M, Wallander J, Oring L, Akst E, Reed JM, Fleischer RC: Adaptive seasonal trend in brood sex ratio: test in two sister species with contrasting breeding systems. Journal of evolutionary biology 2003, 16:510-515.

44. Dijkstra C, Daan S, Buker JB: Adaptive seasonal variation in the sex ratio of kestrel broods. Functional Ecology 1990, 4: |43-I47.

45. Legge S, Hensohn R, Double M, Griffiths R, Cockburn A: Complex sex allocation in the laughing kookaburra. Behavioral Ecology 200I, I 2:524-533.

46. West SA, Sheldon BC: Constraints in the evolution of sex ratio adjustment. Science 2002, 295: I685- I688.

47. Westerdahl H, Bensch S, Hansson B, Hasselquist D, von Schantz T: Sex ratio variation among broods of great reed warblers Acrocephalus arundinaceus. Molecular Ecology 1997, 6:543-548s. 
48. Oddie KR, Reim C: Egg sex ratio and paternal traits: using within individual comparisons. Behavioral Ecology 2002, 13:503-5 I0.

49. Komdeur J, Daan S, Tinbergen J, Mateman C: Extreme adaptive modification in sex ratio of the Seychelles warbler's eggs. Nature 1997, 385:522-525.

50. Badyaev AV, Acevedo Seaman D, Navara KJ, Hill GE, Mendonça MT: Evolution of sex-biased maternal effects in birds: III. Adjustment of ovulation order can enable sex-specific allocation of hormones, carotenoids, and vitamins. Journal of evolutionary biology 2006, 19:1044-1057.

5I. Uller T: Sex-specific sibling interactions and offspring fitnessin vertebrates: patterns and implications for maternal sex ratios. Biological Reviews 2006, 81:207-217.

52. Lovern MB, Passek KM: Sequential alternation of offspring sexfrom successive eggs by female green anoles, Anoles carolinensis. Canadian Journal of Zoology 2002, 80:77-82.

53. Pike TW: Sex ratio manipulation in response to maternal condition in pigeons: Evidence for pre-ovulatory follicle selection. Behavioral Ecology and Sociobiology 2005, 58:407-4I3.

54. Dzus EH, Bortolotti GR, Gerrard JM: Does sex-biased hatching order in bald eagles vary with food resources? Ecoscience 1996 , 3(3):252-258

55. Saino N, Romano M, Ferrari RP, Martinelli R, Møller AP: Maternal antibodies but not carotenoids in barn swallow eggs covary with embryo sex. Journal of evolutionary biology 2003, 16:516-522.

56. Blanco G, Martinez-Padilla J, Serrano D, Davila JA, Vinuela J: Mass provisioning to different-sex eggs within the laying sequence: consequences for adjustment of reproductive effort in a sexually dimorphic bird. Journal of Animal Ecology 2003, 72:83 1-838.

57. Brommer JE, Merilä J, Sheldon BC, Gustafsson L: Natural selection and genetic variation for reproductive reaction norms in a wildbird population. Evolution 2005, 59:|362-I37|.

58. Nussey DH, Clutton-Brock TH, Elston DA, Albon SD, Kruuk LEB: Phenotypic plasticity in a maternal trait in a red deer. Journal of Animal Ecology 2005, 74:387-396.

59. Nussey DH, Postma E, Gienapp P, Visser ME: Selection on heritable phenotypic plasticity in a wild bird population. Science 2005, 3 1 0:304-306.

60. Griffiths R, Double M, Orr K, Dawson R: A DNA test to sex mostbirds. Molecular Ecology 1998, 7:1071-1076.

61. Young RL, Badyaev AV: Evolution of sex-biased maternal effectsin birds: I. Sex-specific resource allocation among simultaneously growing oocytes. Journal of evolutionary biology 2004, I 7: 1355-1366.

62. Wajnberg E: Genetic variation in sex allocation in a parasitic wasp: variation in sex pattern within sequences of oviposition. Entomol Exp Appl 1993, 69:221-229.

63. Yang PX, Arail KY, Jin WZ, Watanabe G, CGroome NP, Taya K: Preovulatory follicles in the ovary as the source of circulatin ginhibin in the duck. General \& Comparative Endocrinology 200I, I 2 I:I56-162.

64. Wang S-Y, Johnson PA: Increase in ovarian a-inhibin gene expression and plasma immunoreactive inhibin level is correlated with adecrease in ovulation rate. Gen Comp Endocrinol 1993, $91: 52-58$

65. Chen CC, Johnson PA: Expression of inhibin alpha andinhibin/ activin beta (3) subunits in the granulosa layer of the large preovulatory follicles of the hen. Biology of Reproduction 1996 55:450-454.
Publish with Biomed Central and every scientist can read your work free of charge

"BioMed Central will be the most significant development for disseminating the results of biomedical research in our lifetime. "

Sir Paul Nurse, Cancer Research UK

Your research papers will be:

- available free of charge to the entire biomedical community

- peer reviewed and published immediately upon acceptance

- cited in PubMed and archived on PubMed Central

- yours - you keep the copyright

Submit your manuscript here:

http://www.biomedcentral.com/info/publishing_adv.asp
BioMedcentral 